\title{
A guide for the selection of routing protocols in WBAN for healthcare applications
}

\author{
V. Bhanumathi* and C. P. Sangeetha
}

*Correspondence:

vbhanu_02@yahoo.com

Anna University Regional

Campus, Coimbatore, Tamil

Nadu, India

\begin{abstract}
In the present scenario, the term wireless body area network (WBAN) is becoming an integral part of human day to day life due its wide variety of applications, especially in the field of healthcare systems. To design such a reliable body area network system, there are a number of factors to be considered both in hardware and software levels. One of such factors still developing is the design and the analysis of routing protocols in the network layer. Routing protocols are a set of protocols which can identify and maintain the routes in the network so that the data can be exchanged between the nodes efficiently. Hence, routing protocol plays a vital role in the wireless sensor networks for reliable communication between the sensor nodes. In this paper, different routing protocols for body area networks are surveyed and observed that they are affected by factors like energy, network topology, various quality of services (QoS) in the nodes, node temperature, transmission range of nodes, human posture, etc. An evocative taxonomy of protocols is presented such as cluster-based, cross-layered, postural movement based, QoS aware and temperature-aware routing protocols. From the survey, it is found that the selection of a routing protocol is application dependent. For example, the energy efficient protocols like reinforcement learning based routing with QoS support or wireless autonomous spanning tree protocol can be used for daily health monitoring systems due to its high packet delivery ratio. If the system is for in vivo networks, routing algorithm for network of homogeneous and Id-less biomedical sensor nodes or mobility-supporting adaptive threshold-based Thermal-aware energy-efficient multi-hop protocols are the suitable ones. For critical and emergency cases, where accuracy with little delay is the major concern, the protocols like critical data routing, reliability aware routing, data-centric multi objective QoS-aware routing protocol, etc. can be rightly chosen. This entire survey paper can be used by the researchers as a reference for studying various WBAN routing protocols, especially in the field of medical health care systems.
\end{abstract}

Keywords: Quality of service, Routing protocols, Wireless body sensor networks

\section{Introduction}

Wireless body area networks (WBANs) include a collection of body sensor nodes that are low power, invasive or non-invasive, light-weight devices which are either worn on the body or implanted inside the body. The architecture of WBAN [1] can be considered as three different tiers, namely: Tier- 1 as Intra-BAN, Tier-2 as Inter-BAN and Tier-3 as Extra-BAN as shown in Fig. 1. In Tier-1, the body sensor nodes collect the data and send to the coordinator. In Tier-2, the coordinator processes the received data and sends the

(c) The Author(s) 2017. This article is distributed under the terms of the Creative Commons Attribution 4.0 International License (http://creativecommons.org/licenses/by/4.0/), which permits unrestricted use, distribution, and reproduction in any medium, provided you give appropriate credit to the original author(s) and the source, provide a link to the Creative Commons license, and indicate if changes were made. 


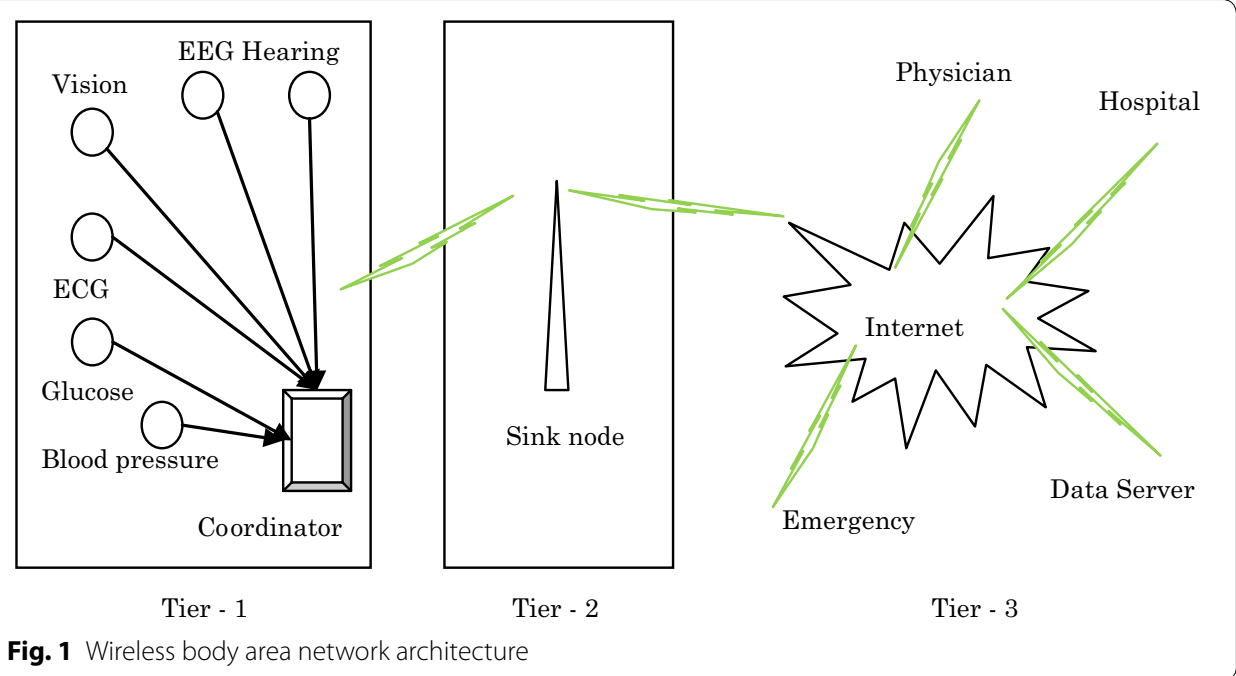

information towards the sink node. From the sink node the packets are transmitted to the corresponding health-center through internet or other communication techniques.

According to the survey conducted by the Economic and Social Affairs Department of United Secretariat [2], after 10 years people with age above 65 will be approximately $15 \%$ of total world population. As, older people are more exposed to medical health issues, the need for low cost health monitoring devices [3] becomes a major part human life.

WBAN is actually a subset of conventional wireless sensor networks (WSNs), which can be used for early detection of various diseases, for real-time patient monitoring of elderly people, etc. The body sensor node is either worn on the body surface or implanted inside the body. The sensed data is sent to the Base Station and is then forwarded to the sink node. The sink node is responsible for sending the information to its corresponding healthcare center.

The reliability and efficiency of WBAN depend on how the system responds quickly and accurately, to send and receive the data between the nodes, which eventually depends on the selected routing protocols or algorithms. The process of sending information from either an in-body or an on-body sensor node includes the radiation emitted from wireless transceivers which is similar to WSNs.

Although the routing protocols that are used in WSNs have been under study for past few years, these protocols cannot be used for WBANs due to its stringent requirements. For WSNs, the main focus is on minimal routing overhead and maximal throughput than reduced energy consumption [4]. Also, WSNs are mostly homogenous networks, the WBANs are heterogeneous too [5].

In this article, a comprehensive review of the existing recent routing protocols/algorithms is discussed. "The required evaluation metrics for healthcare applications" section discusses the performance metrics that should be considered for WBANs. The classification of the existing routing protocols is explained in "Classification of routing protocols" and "Future challenges and comparative analysis of routing protocols" sections gives the future challenges and a comparative analysis of different selected protocols. Finally, "Conclusions" concludes the survey. 


\section{The required evaluation metrics for healthcare applications}

In order to identify the important metrics that have to be considered in WBANs during the design process, a general overview about the routing challenges in WBANs should be studied. The certain routing issues and challenges include network topology, postural body movements, limited resources, quality of service metrics, radiation and interference, global network lifetime, heterogeneous environment, etc. By analyzing all these factors we can conclude and list the important performance metrics to be considered while implementing the whole WBAN. The following section defines the metrics:

- Network lifetime defines the total operation time of the network until the last node is dead.

- Path loss is the difference between the transmitted power at the source node and received power at sink node.

- Stability period is the time before first node die.

- Residual energy is the difference between initial energy and used energy during the operation of the network.

- End-to-end delay is the average time taken by a data packet to reach the sink from the source node.

- Packet delivery ratio is determined by number packets obtained at the sink divided by the number of packets send from the source.

\section{Classification of routing protocols}

The classification of routing protocols can be done in different categories that correlate with the routing challenges of WBAN. The following section gives an overview about the existing protocols, which can be categorized as Cluster-based, Cross-layered, Postural movement based, quality of services (QoS) aware and Temperature-aware routing algorithms [6] as shown in Fig. 2.

\section{Cluster-based routing protocols}

In both WSNs and WBANs, the limited energy source is the main constraint to be analyzed. Hence, several efficient cluster based schemes are proposed for both networks to minimize the power consumption and maximize the network lifetime [7]. While comparing hybrid indirect transmission [8] to power-efficient gathering in sensor information systems [9] and low-energy adaptive clustering hierarchy (LEACH) [10], it consumes less amount of energy if the number of nodes are small. However, AnyBody [11] protocol is better than LEACH, as the numbers of clusters remain constant with an increase in the number of nodes, but LEACH does not. Also, the installation cost is also less with AnyBody. The Table 1 shows an overview of the existing cluster-based protocols.

\section{Cross-layered routing protocols}

These protocols use the concept of cross layering [13] which is already addressed in WSNs, where each layer (adjacent or non-adjacent) in the protocol stack shares their information unlike in the strict layered model. In WBANs, we can utilize the cross layering concept between network and medium access control (MAC) layers for routing and 


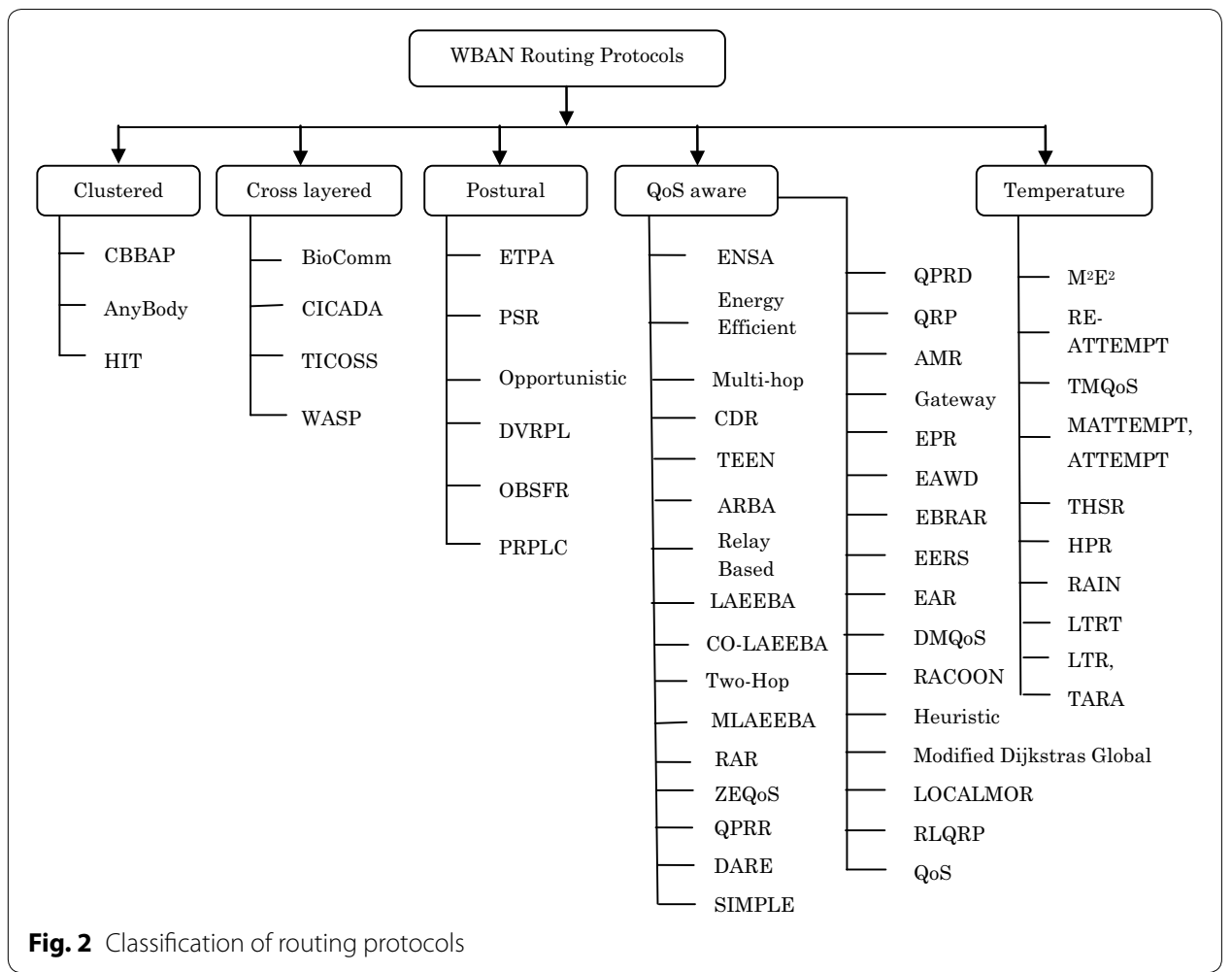

Table 1 clustered routing protocols in body area networks

\begin{tabular}{|c|c|c|c|c|}
\hline SI. no. & Protocol [ref. no.] & Goal & Performance metrics & Compared with \\
\hline 1 & $\begin{array}{l}\text { Cluster based body area } \\
\text { protocol (CBBAP) [12] }\end{array}$ & $\begin{array}{l}\text { To enhance the overall } \\
\text { energy efficiency of } \\
\text { WBAN }\end{array}$ & $\begin{array}{l}\text { Throughput, residual } \\
\text { energy, number of live } \\
\text { nodes }\end{array}$ & LEACH \\
\hline 2 & AnyBody protocol [1 1] & $\begin{array}{l}\text { To divide the network } \\
\text { into clusters and to } \\
\text { efficiently send packets } \\
\text { from source to sink }\end{array}$ & $\begin{array}{l}\text { Number of clusters, } \\
\text { average cluster size, } \\
\text { number of transmitted } \\
\text { messages to setup }\end{array}$ & LEACH \\
\hline 3 & $\begin{array}{l}\text { Hybrid indirect transmis- } \\
\text { sion (HIT) [8] }\end{array}$ & $\begin{array}{l}\text { To maintain longer } \\
\text { network life }\end{array}$ & $\begin{array}{l}\text { Network longevity, } \\
\text { network delay, average } \\
\text { energy dissipation, } \\
\text { average energy dis- } \\
\text { sipation } \times \text { average } \\
\text { delay product }\end{array}$ & LEACH, PEGASIS, direct \\
\hline
\end{tabular}

thereby can upgrade the overall network performance. Table 2 shows the different crosslayered routing protocols. Considering the detailed analysis of cross layered protocols, Cascading Information retrieval by controlling access with distributed slot assignment (CICADA) [14] and time zone coordinated sleep scheduling [15] have less power consumption. Wireless autonomous spanning tree protocol (WASP) [16] has better packet delivery ratio and CICADA has less delay.

\section{Postural movement based routing protocols}

The body postural movements affect the network topology of the network, which results in link disconnection. The researchers introduced a cost function that is periodically 
Table 2 Cross layered protocols in body area networks

\begin{tabular}{|c|c|c|c|c|}
\hline Sl. no. & Protocol [ref. no.] & Goal & Performance metrics & Compared with \\
\hline 1 & $\begin{array}{l}\text { Biocomm and } \\
\text { Biocomm-D [17] }\end{array}$ & $\begin{array}{l}\text { To optimize the overall } \\
\text { performance of the } \\
\text { in vivo network }\end{array}$ & $\begin{array}{l}\text { Maximum temperature } \\
\text { rise, average energy con- } \\
\text { sumption, packet delivery } \\
\text { delay, percentage of } \\
\text { injected packets dropped, } \\
\text { cumulative network } \\
\text { throughput }\end{array}$ & $\begin{array}{l}\text { Shortest hop routing } \\
\text { hotspot preventive } \\
\text { routing }\end{array}$ \\
\hline 2 & $\begin{array}{l}\text { Cascading informa- } \\
\text { tion retrieval by } \\
\text { controlling access } \\
\text { with distributed } \\
\text { slot assignment } \\
\text { (CICADA) [14] }\end{array}$ & $\begin{array}{l}\text { To introduce less delay } \\
\text { and low energy con- } \\
\text { sumption }\end{array}$ & End to end delay & - \\
\hline 3 & $\begin{array}{l}\text { TImezone coordinated } \\
\text { sleep scheduling } \\
\text { (TICOSS) [15] }\end{array}$ & $\begin{array}{l}\text { To improve } 802.15 .4 \\
\text { through the division of } \\
\text { the network into time } \\
\text { zones }\end{array}$ & Network lifetime & $\begin{array}{l}\text { IEEE 802.15.4 without } \\
\text { TICOSS }\end{array}$ \\
\hline 4 & $\begin{array}{l}\text { Wireless autonomous } \\
\text { spanning tree proto- } \\
\text { col (WASP) [16] }\end{array}$ & $\begin{array}{l}\text { To reduce power } \\
\text { consumption, network } \\
\text { delay and packet loss } \\
\text { rate }\end{array}$ & End to end delay & $\begin{array}{l}\text { CSMA with fixed } \\
\text { routing }\end{array}$ \\
\hline
\end{tabular}

updated for choosing the best route to forward packets to the sink. The protocols listed in Table 3 are the existing postural movement based routing protocols. Among the discussed protocols, on-body store and flood routing (OBSFR) [18] has better performance in reducing the packet delivery delay, but opportunistic postural movement based routing protocol has lower energy consumption than others.

\section{QoS aware routing protocols}

Presently, there are a number of diverse QoS aware protocols available in WSNs, which cannot be as such implemented in WBANs, but by considering its unique curbs it can. In WBANs different data types require different QoS [24]. Hence the proposed protocols should be aware of different types of QoS metrics for various types of data. The various QoS aware routing protocols are shortlisted as given in Table 4.

The comparative analysis has shown that energy-aware peering routing protocol (EPR) [45], QoS-aware peering routing protocol for delay sensitive data (QPRD) [41] and QoS aware peering routing protocol for reliability sensitive data (QPRR) [38] have less power consumption when compared to other protocols. Some protocols do not consider energy consumption, while others. One of the most used QoS aware protocols is data-centric multi objective QoS-aware routing protocol (DMQoS) [50] because it can decrease the delay for delay-sensitive information, and similarly, it can provide reliable routing for reliable-sensitive information. The other QoS-aware protocols are used or selected for a particular network, according to the data type and its QoS requirements.

\section{Temperature-aware routing protocols}

The antenna radiation, its absorption and interference are the major challenges to be considered while designing a body sensor network, since the radiated fields cause a temperature rise of node's electronic circuitry. The field of radiation also has a strong 
Table 3 Postural routing protocols in body area networks

\begin{tabular}{|c|c|c|c|c|}
\hline $\begin{array}{l}\text { Sl. } \\
\text { no. }\end{array}$ & Protocol [ref. no.] & Goal & Performance metrics & Compared with \\
\hline 1 & $\begin{array}{l}\text { Energy efficient thermal } \\
\text { and power aware rout- } \\
\text { ing (ETPA) [19] }\end{array}$ & $\begin{array}{l}\text { To reduce the node's } \\
\text { temperature and to } \\
\text { prevent the hotspot } \\
\text { formation }\end{array}$ & $\begin{array}{l}\text { Packet hop count, packet } \\
\text { delivery ratio, packet } \\
\text { delay, average tem- } \\
\text { perature rise of nodes in } \\
\text { the network, scalability, } \\
\text { depletion time of the } \\
\text { first node mobility }\end{array}$ & PRPLC \\
\hline 2 & $\begin{array}{l}\text { Prediction based secure } \\
\text { and reliable routing } \\
\text { framework (PSR) [20] }\end{array}$ & $\begin{array}{l}\text { To provide secure and } \\
\text { reliable routing from } \\
\text { various data attacks }\end{array}$ & $\begin{array}{l}\text { Packet dropping rate, } \\
\text { authentication cost }\end{array}$ & Backbone protoco \\
\hline 3 & Opportunistic routing [21] & $\begin{array}{l}\text { To increase the network } \\
\text { lifetime from the } \\
\text { motion of body parts }\end{array}$ & $\begin{array}{l}\text { Average energy consump- } \\
\text { tion per bit }\end{array}$ & $\begin{array}{l}\text { Single hop, multi } \\
\text { hop }\end{array}$ \\
\hline 4 & $\begin{array}{l}\text { Distance vector routing } \\
\text { with postural link costs } \\
\text { (DVRPLC) [22] }\end{array}$ & $\begin{array}{l}\text { To decrease end to end } \\
\text { delay }\end{array}$ & $\begin{array}{l}\text { Average delay, packet } \\
\text { delivery ratio, packet hop } \\
\text { count }\end{array}$ & $\begin{array}{l}\text { Probabilistic proto- } \\
\text { col (PROPHET), } \\
\text { opportunistic } \\
\text { protocol, UTILITY }\end{array}$ \\
\hline 5 & $\begin{array}{l}\text { On-body store and flood } \\
\text { routing (OBSFR) [18] }\end{array}$ & $\begin{array}{l}\text { To provide better rout- } \\
\text { ing delay and hop } \\
\text { count }\end{array}$ & $\begin{array}{l}\text { End-to-end packet } \\
\text { delay (PD), number of } \\
\text { transmissions per packet } \\
\text { (NTPP), packet delivery } \\
\text { ratio (PDR) }\end{array}$ & $\begin{array}{l}\text { PROPHET, on-body } \\
\text { store and flood } \\
\text { routing (OBSFR) }\end{array}$ \\
\hline 6 & $\begin{array}{l}\text { Probabilistic routing } \\
\text { with postural link costs } \\
\text { (PRPLC) [23] }\end{array}$ & $\begin{array}{l}\text { To reduce end to end } \\
\text { delay }\end{array}$ & $\begin{array}{l}\text { Average delay, packet } \\
\text { delivery ratio }\end{array}$ & PROPHET, OBSFR \\
\hline
\end{tabular}

impact on the human body [57] that may damage the human tissues due to its continuous exposure. The goal of all temperature-aware protocols is to decrease the temperature rise of in-body sensor nodes by avoiding routing through hotspots. Table 5 discusses the existing temperature-aware protocols. From the comparison of different protocols, it is seen that LTRT [58] performs much better than others while TARA [59] performs worst. In terms of temperature rise, HPR [60] shows less temperature rise in comparison with others. Finally, the latest $\mathrm{M}^{2} \mathrm{E}^{2}$ protocol [61] has proved that it is the best one among all thermal aware protocols, suitable for heterogeneous, multimode, energy efficient body sensor networks.

\section{Future challenges and comparative analysis of routing protocols}

The scope of this article is to open up new research areas in WBAN domain for routing protocol designs. Among all the routing protocols, the cluster based protocol HIT [8] aims at maximizing the network lifetime, but it does not consider the packet delivery ratio which is an important QoS metric. The second one, AnyBody [11] protocol considers the delivery ratio, but does not consider average delay, mobility and energy consumption. It leads to poor security measures. In order to optimize the performance of sensor networks for some specific applications, it is necessary to include the aforementioned metrics also in the design considerations.

The cross layered concept is attaining great significance and interest among researchers due to its flexibility and effectiveness in sensor networks. The future research work aims at improving the reliability of CICADA [14] which performs better in terms of energy efficiency and average delay when compared to other cross layered protocols. 


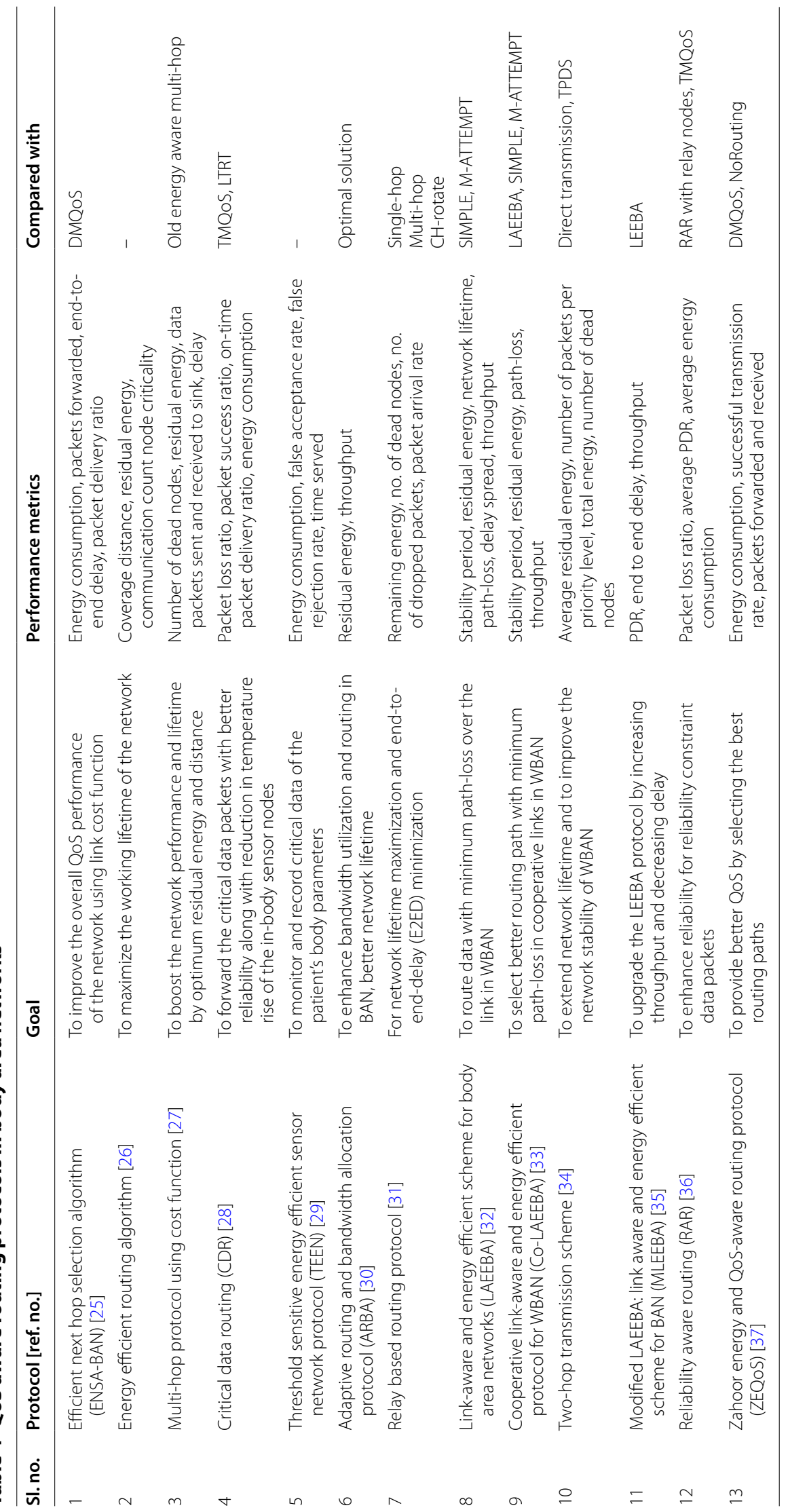




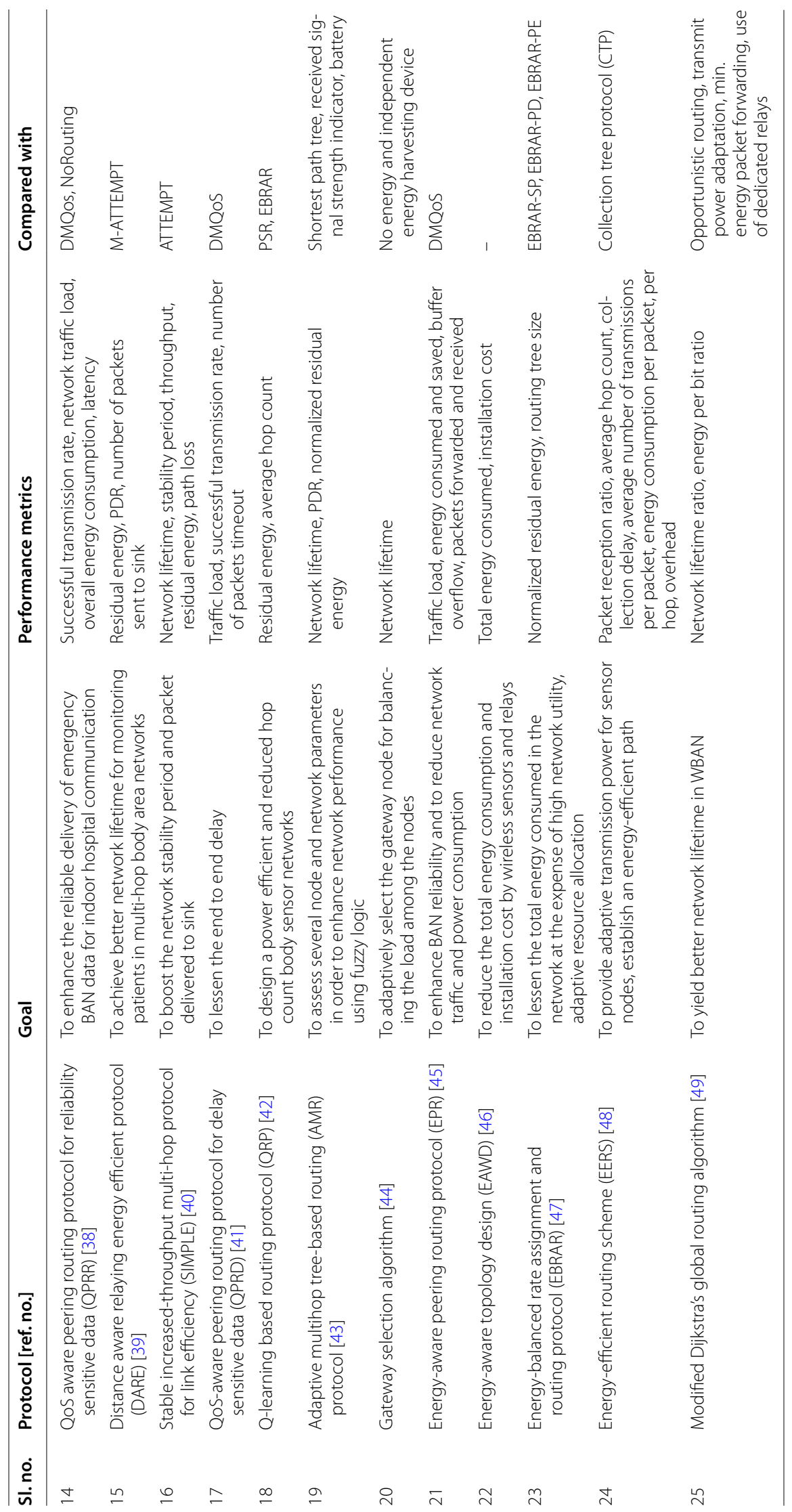




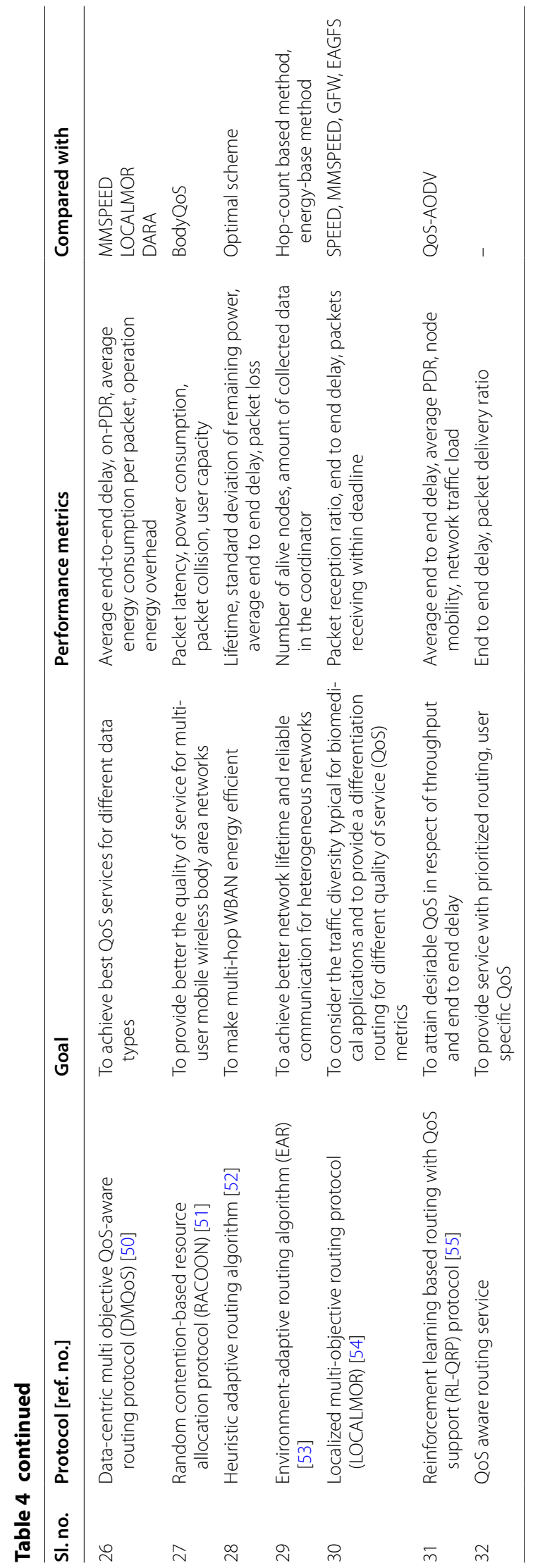




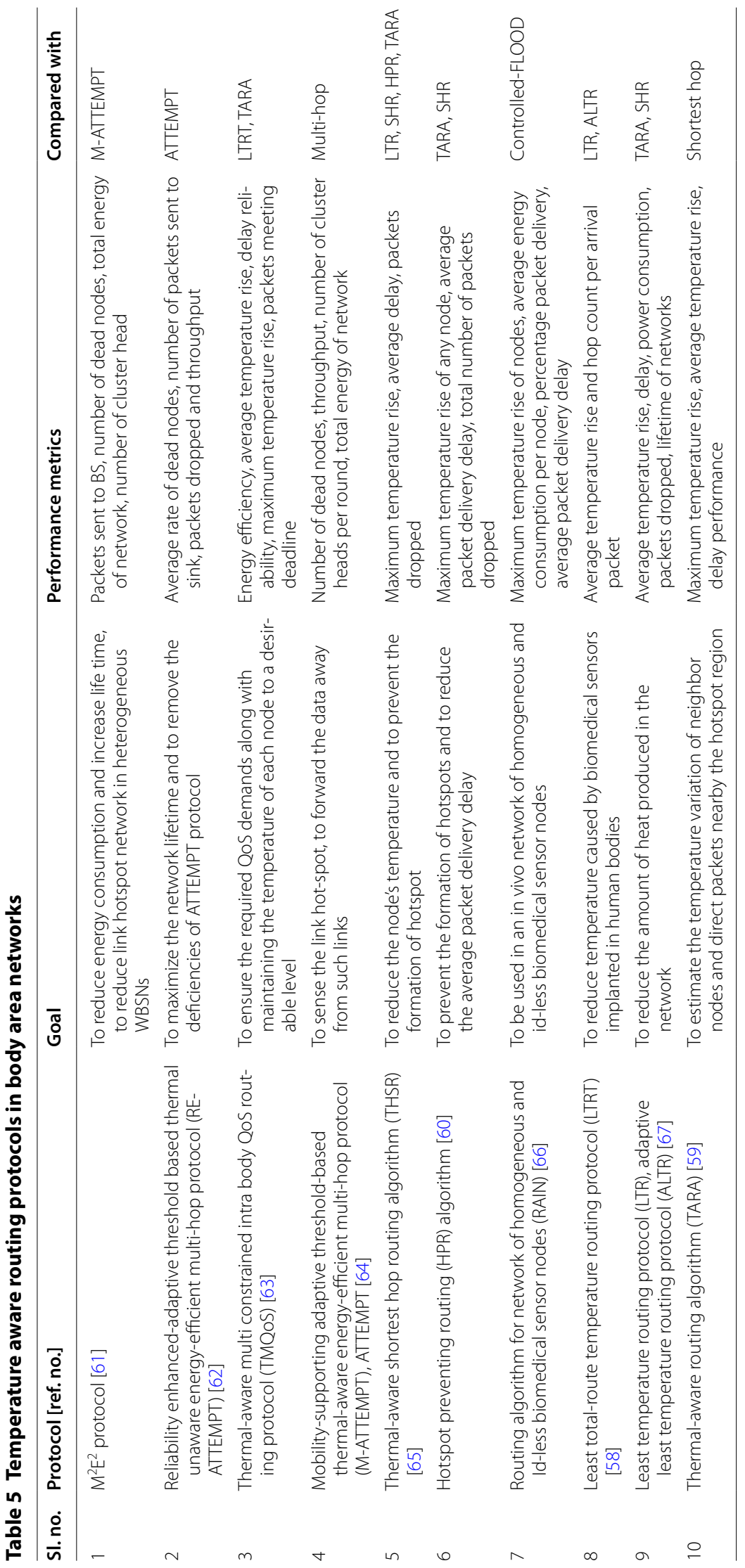


When IEEE 802.15.4 standard networks are used, it will be good if the TICOSS [15] protocol is redesigned for reducing the average delay which is not considered in the existing one. If the entire network performance is to be optimized, the choice will be the Biocomm protocols along with new techniques to reduce the node temperature. Hence, the scope for research in this area is very much wide enough to work with. The comparative analysis of postural movement protocols has shown that, none of them considered the thermal effects of nodes and QoS issues together. Therefore, the future protocols could be proposed in such a way that, it could achieve better QoS parameters along with techniques to reduce the node temperature rise and methods to counter security attacks. The survey on QoS aware protocols unveils various research areas for future work because of its importance. Every new protocol, which has been designed, is meant for addressing the limitation of the previous one. For example, in routing service framework [56] and reinforcement learning based routing with QoS support [55] the energy consumption is not considered, but it is taken into account in the remaining protocols.

In almost, all the existing QoS aware protocols, only the QoS metrics are examined, without concentrating on the human body movements and temperature rise of implanted devices. The proposed temperature aware protocols perform better by reducing the temperature rise due to radiation from antenna and other node circuitry. Along with the thermal issue and power consumption, it will be better if these protocols can also address the routing issues like shortest path as in QoS aware.

Table 6 summarizes the comparison between some of the routing protocols used in WBAN. From the analysis, it is seen that almost all the protocols have considered different QoS metrics for their performance analysis. Hence, choosing the protocol for a WBAN system depends on the particular application of the system; whether it should be energy efficient, good reliable one or it should reduce the temperature of the node circuitry. Table 7 lists the pros and cons and the application domain of each protocols used in body area networks. This table helps to choose a particular protocol based on the QoS requirements. For example, if the application of the proposed system is patient monitoring in hospitals, then the protocols like WASP [16] or TICOSS [15] can be selected due to its high packet delivery ratio and low average delay. If the sensors are implanted within the body, then the protocols like Co-LEEBA [33], TARA [59], or routing algorithm for network of homogeneous and Id-less biomedical sensor nodes (RAIN) [66] can be chosen. If the network is heterogeneous one, then M-ATTEMPT or $\mathrm{M}^{2} \mathrm{E}^{2}$ can be used.

\section{Conclusions}

Wireless body area network is a part of wireless sensor network, with a number of nodes deployed within and on the surface of human body to measure different biological parameters for a particular application. In this survey article, various existing routing protocols that are used in WBANs are categorized and briefly analyzed from the available articles between the years 2002-2016. It is seen that the routing protocol plays a vital role in the design process of every efficient, reliable, low cost wireless 
Table 6 Comparative analysis of routing protocols

\begin{tabular}{|c|c|c|c|c|c|c|}
\hline SI. no. & $\begin{array}{l}\text { Routing } \\
\text { protocol }\end{array}$ & $\begin{array}{l}\text { Type of } \\
\text { protocol }\end{array}$ & $\begin{array}{l}\text { Average } \\
\text { delay }\end{array}$ & $\begin{array}{l}\text { Energy } \\
\text { consumption }\end{array}$ & $\begin{array}{l}\text { Packet } \\
\text { delivery } \\
\text { ratio }\end{array}$ & $\begin{array}{l}\text { Average } \\
\text { temperature } \\
\text { rise }\end{array}$ \\
\hline 1 & HIT [8] & Clustered & Very Low & Low & * & * \\
\hline 2 & AnyBody [11] & Clustered & * & $*$ & Very high & * \\
\hline 3 & WASP [16] & Cross-layered & Low & Low & Very high & * \\
\hline 4 & CICADA [14] & Cross-layered & Low & Low & $*$ & * \\
\hline 5 & TICOSS [15] & Cross-layered & $*$ & Low & High & * \\
\hline 6 & $\begin{array}{l}\text { Routing service } \\
\text { framework [56] }\end{array}$ & QoS-aware & * & * & Moderate & * \\
\hline 7 & RL-QRP [55] & QoS-aware & High & $*$ & High & * \\
\hline 8 & ZEQoS [37] & QoS-aware & $*$ & High & High & * \\
\hline 9 & RL-QRP [55] & QoS-aware & Low & Low & High & * \\
\hline 10 & ENSA-BAN [25] & QoS-aware & Very low & Low & Very high & * \\
\hline 11 & Co-LEEBA [33] & QoS-aware & $*$ & Low & High & * \\
\hline 12 & DMQoS [50] & QoS-aware & Low & Moderate & High & * \\
\hline 13 & LOCALMOR [54] & QoS-aware & Low & Low & High & * \\
\hline 14 & TARA [59] & Temperature-aware & Very High & High & Low & Low \\
\hline 15 & LTRT [58] & Temperature-aware & * & $*$ & Very high & Low \\
\hline 16 & RAIN [66] & Temperature-aware & Moderate & Low & High & Low \\
\hline 17 & M-ATTEMPT [64] & Temperature-aware & Low & Low & High & Low \\
\hline 18 & $M^{2} E^{2}[61]$ & Temperature-aware & Low & Very low & Very high & Low \\
\hline 19 & TMQoS [63] & Temperature-aware & Very low & Very low & High & Moderate \\
\hline 20 & ETPA [19] & Postural & High & Low & High & Low \\
\hline 21 & PSR [20] & Postural & Low & High & Moderate & $*$ \\
\hline
\end{tabular}

* Not applicable

body sensor networks. Based on the structure and nature of networks, the routing protocols for WBANs are categorized as cluster-based, cross-layered, postural movement based QoS aware and temperature-aware protocols. It is observed that there is no strict classification of protocols is possible since most of them aims or results in achieving the challenges of sensor networks. It is also concluded that each protocol is application dependent, i.e., the protocols used for daily monitoring and the critical medical cases are different. The future directions for each group of protocols are also presented which helps the researchers to focus on their interested area. Also, a comparative study of different protocols has been examined so that an appropriate protocol can be selected according to the targeted application. This survey will benefit the researchers to study the existing routing protocols for WBANs in the field of healthcare systems.

The Future work includes the design and implementation of a body sensor prototype with a newly designed routing protocol, which will be highly energy efficient and reliable one for rehabilitation of old age people using a microcontroller based system with suitable sensors. 


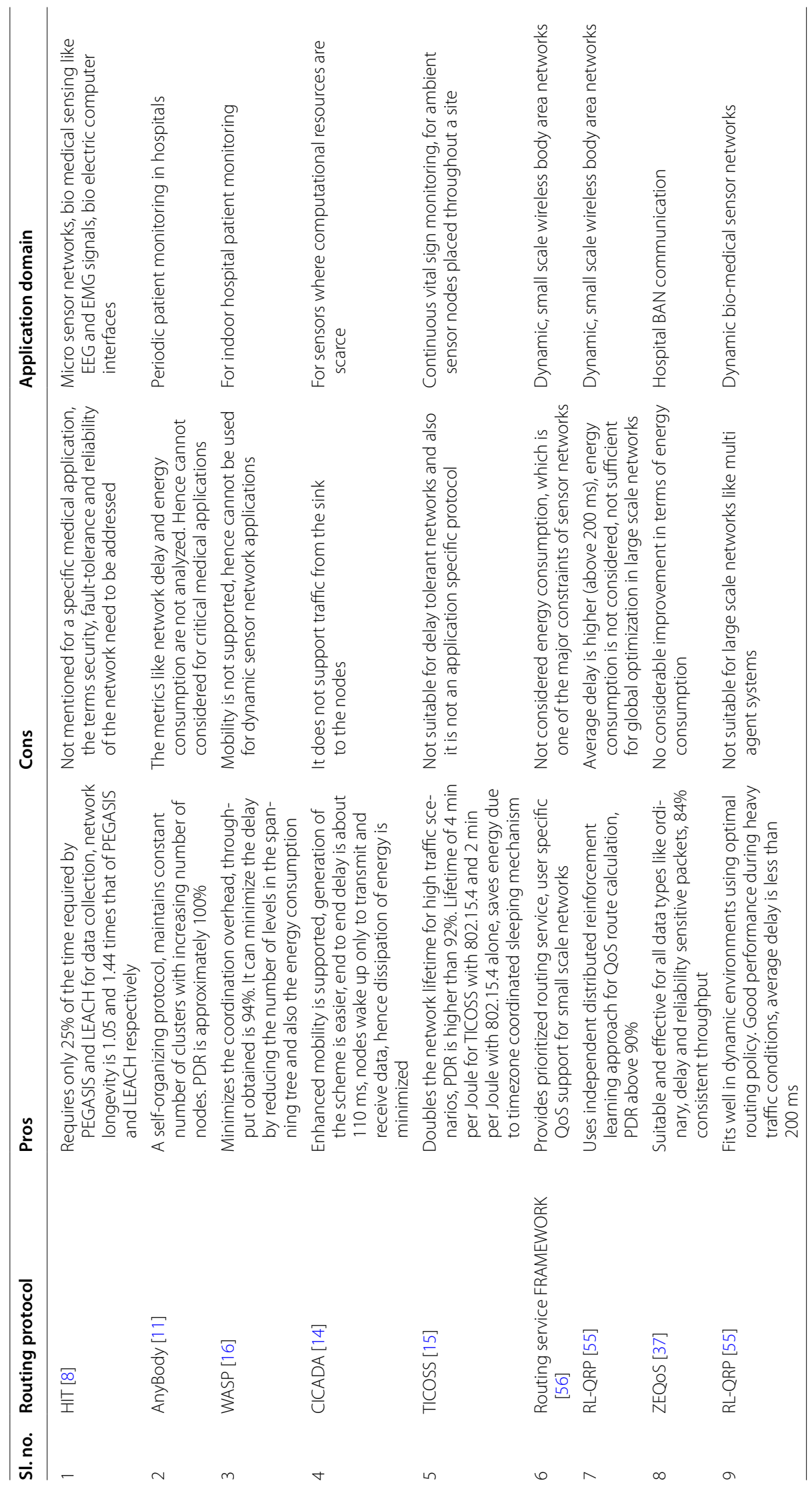




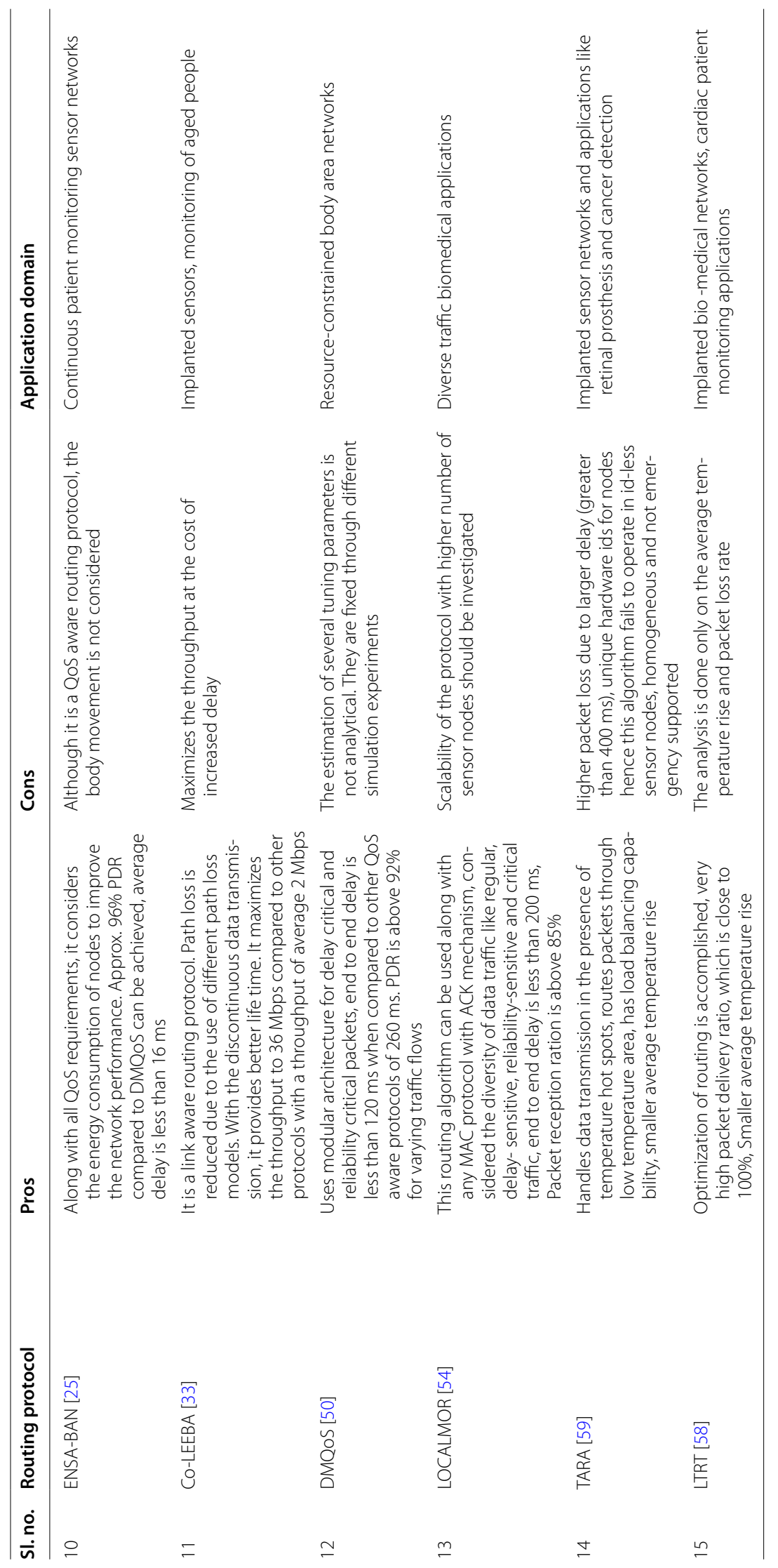




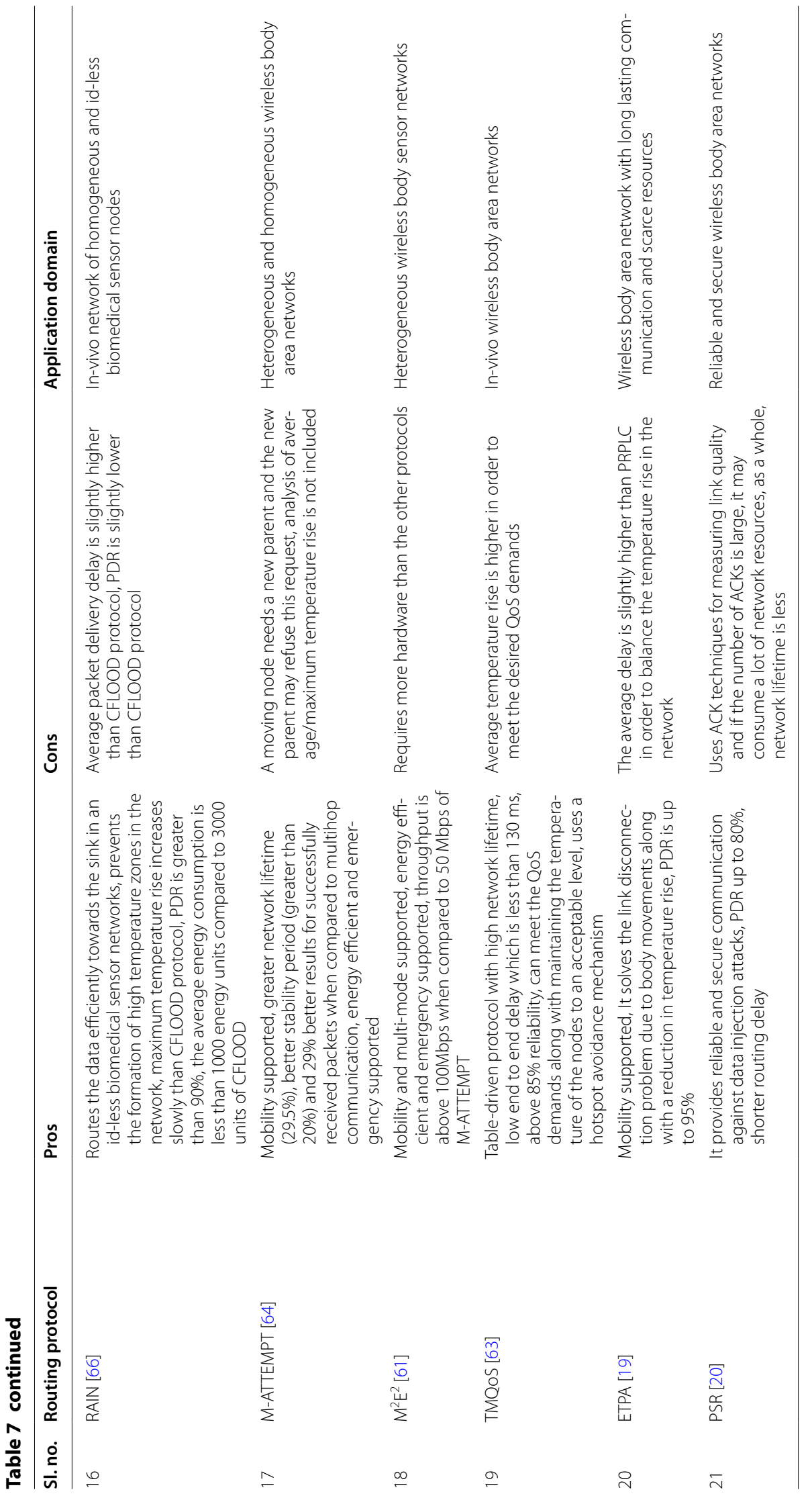




\begin{abstract}
Abbreviations
WBAN: wireless body area network; QoS: quality of services; RL-QRP: reinforcement learning based routing with Qos support; WASP: wireless autonomous spanning tree protocol; RAIN: routing algorithm for network of homogeneous and Id-less biomedical sensor nodes; M-ATTEMPT: mobility-supporting adaptive threshold-based thermal-aware energy-efficient multi-hop protocols; CDR: critical data routing; RAR: reliability aware routing; DMQoS: data-centric multi objective QoS-aware routing protocol; LEACH: low-energy adaptive clustering hierarchy; CBBAP: cluster based body area protocol; HIT: hybrid indirect transmission; PEGASIS: power-efficient gathering in sensor information systems; MAC: medium access control; CICADA: cascading information retrieval by controlling access with distributed slot assignment; TICOSS: time zone coordinated sleep scheduling; OBSFR: on-body store and flood routing; ETPA: energy efficient thermal and power aware routing; PSR: prediction based secure and reliable routing framework; DVRPLC: distance vector routing with postural link costs; PRPLC: probabilistic routing with postural link costs; ENSA-BAN: efficient next hop selection algorithm; TEEN: threshold sensitive energy efficient sensor network protocol; ARBA: adaptive routing and bandwidth allocation protocol; LAEEBA: link-aware and energy efficient scheme for body area networks; Co-LAEEBA: cooperative link-aware and energy efficient protocol for WBAN; MLEEBA: modified LAEEBA: link aware and energy efficient scheme for BAN; ZEQOS: Zahoor energy and QOS-aware routing protocol; QPRR: QOS aware peering routing protocol for reliability sensitive data; DARE: distance aware relaying energy efficient protocol; SIMPLE: stable increased-throughput multi-hop protocol for link efficiency; QPRD: QoS-aware peering routing protocol for delay sensitive data; QRP: Q-learning based routing protocol; AMR: adaptive multihop tree-based routing; EPR: energy-aware peering routing protocol; EAWD: energy-aware topology design; EBRAR: energy-balanced rate assignment and routing protocol; EERS: energy-efficient routing scheme; MDGRA: modified Dijkstra's global routing algorithm [49]; RACOON: random contention-based resource allocation protocol; EAR: environment-adaptive routing algorithm; LOCALMOR: localized multi-objective routing protocol; RE-ATTEMPT: reliability enhanced-adaptive threshold based thermal unaware energy-efficient multi-hop protocol; TMQoS: thermalaware multi constrained intra body QoS routing protocol; M-ATTEMPT: mobility-supporting adaptive threshold-based thermal-aware energy-efficient multi-hop protocol; THSR: thermal-aware shortest hop routing algorithm; HPR: hotspot preventing routing; LTRT: least total-route temperature routing protocol; LTR: least temperature routing protocol; ALTR: adaptive least temperature routing protocol; TARA: thermal-aware routing algorithm.
\end{abstract}

\title{
Authors' contributions
}

VB conducted the survey work, analyzed the schemes and drafted the manuscript. CPS participated in literature review and helped to draft the manuscript. Both authors read and approved the final manuscript.

\section{Authors' information}

V. Bhanumathi received the Bachelor Degree in Electronics and Communication Engineering from Madras University, Master Degree in Communication Systems from Anna University, Chennai and Ph.D. in Information and Communication Engineering from Anna University, Chennai. She is currently working as an Assistant Professor in the Department of Electronics and Communication Engineering, Anna University, Regional Campus, Coimbatore. She has published her works in various International Journals and conferences. Her areas of interest are Wireless Communication, VLSI Design, Network Security, and Digital Communication.

C. P. Sangeetha received her Bachelor Degree in Electronics and Communication and Master Degree from Cochin University of Science and Technology, Kerala. She is currently doing her Ph.D. in Information and Communication Engineering, Anna University, Chennai. She has worked as a Lecturer in Electronics and Communication Engineering, Toc $\mathrm{H}$ Institute of Science and Technology, Cochin for 8 years. She has published a number of papers in various International Journals and conferences. Her areas of interest include wireless sensor networks and mobile communications.

\section{Acknowledgements}

We would like to thank the editors and the reviewers for their noble comments and constructive criticisms for improvement of the manuscript.

\section{Competing interests}

The authors declare that they have no competing interests.

\section{Publisher's Note}

Springer Nature remains neutral with regard to jurisdictional claims in published maps and institutional affiliations.

Received: 24 December 2016 Accepted: 25 June 2017

Published online: 10 August 2017

\section{References}

1. Movassaghi S, Abolhasan M, Lipman J, Smith D, Jamalipour A (2014) Wireless body area networks: a survey. IEEE Commun Surv Tutor 16(3):1658-1686. doi:10.1109/SURV.2013.121313.00064

2. United Nations (2013) World population prospects: the (2012) revision. https://esa.un.org/unpd/wpp/Publications/ Files/WPP2012_Methodology.pdf. Accessed 13 June 2013

3. Chen C, Knoll A, Wichmann HE, Horsch A (2013) A review of three-layer wireless body sensor network systems in healthcare for continuous monitoring. J Mod Internet Things 2(3):24-34

4. Ullah S, Higgins H, Braem B, Latre B, Blondia C, Moerman I, Saleem S, Rahman Z, Kwak KS (2012) A comprehensive survey of wireless body area networks. J Med Syst 36:1065-1094. doi:10.1007/s10916-010-9571-3

5. Latre B, Braem B, Moerman I, Blondia C, Demeester P (2011) A survey on wireless body area networks. Wirel Netw 17(1):1-18. doi:10.1007/s11276-010-0252-4 
6. Bangash J, Abdullah AH, Anisi MH, Khan AW (2014) A survey of routing protocols in wireless body sensor networks. Sensors 14(1):1322-1357. doi:10.3390/s140101322

7. Heinzelman WB, Chandrakasan AP, Balakrishnan H (2002) An application-specific protocol architecture for wireless microsensor networks. IEEE Trans Wirel Commun 1(4):660-670. doi:10.1109/TWC.2002.804190

8. Culpepper BJ, Dung L, Moh M (2004) Design and analysis of hybrid indirect transmissions (HIT) for data gathering in wireless micro sensor networks. ACM SIGMOBILE Mob Comput Commun Rev 8(1):61-83. doi:10.1145/980159.980169

9. Lindsey S, Raghavendra CS (2002) PEGASIS: power-efficient gathering in sensor information systems. Proceedings of the IEEE aerospace conference proceedings. Big Sky, Montana, pp 1125-1130

10. Heinzelman WR, Chandrakasan A, Balakrishnan H (2000) Energy-efficient communication protocol for wireless microsensor networks. In: Proceedings of the IEEE proc. Hawaii int'l. conf. sys. sci, pp 1-10

11. Watteyne T, Augé-Blum I, Dohler M, Barthel D (2007) Anybody: a self-organization protocol for body area networks. In: Proceedings of the ICST 2nd international conference on body area networks (BodyNets '07), Brussels, ICST Belgium, pp 6:1-6:7

12. Alghamdi TA (2016) Cluster based energy efficient routing protocol for wireless body area networks. Trends Appl Sci Res 11(1):12-16. doi:10.3923/tasr.2016.12.18

13. Mendes LDP, Rodrigues JJPC (2011) A survey on cross-layer solutions for wireless sensor networks. J Netw Comput Appl 34(2):523-534. doi:10.1016/j.jnca.2010.11.009

14. Latre B, Braem B, Moerman I, Blondia C, Reusens E, Joseph W, Demeester P (2007) A low-delay protocol for multihop wireless body area networks. In: Proceedings of the 4 th annual international conference mobile and ubiquitous systems: networking and services. Philadelphia, PA, USA, pp 1-8. doi:10.1109/MOBIQ.2007.4451060

15. Ruzzelli AG, Jurdak R, O'Hare GM, Van Der Stok P (2007) Energy-efficient multi-hop medical sensor networking. In: Proceedings of the 1st ACM SIGMOBILE international workshop on systems and networking support for healthcare and assisted living environments. San Juan, Puerto Rico, ACM New York, USA, pp 37-42. doi:10.1145/1248054.1248064

16. Braem B, Latre B, Moerman I, Blondia C, Demeester P (2006) The wireless autonomous spanning tree protocol for multihop wireless body area networks. In: Proceedings of the 3rd annual international IEEE conference on mobile and ubiquitous systems: networking and services. San Jose, CA, USA, pp 1-8. doi:10.1109/MOBIQ.2006.340421

17. Anirban B, Bassiouni MA (2009) Biocomm - a cross-layer medium access control (MAC) and routing protocol co-design for biomedical sensor networks. Int J Parallel Emergent Distrib Syst 24(1):85-103. doi:10.1080/17445760802335345

18. Quwaider M, Biswas S (2009) On-body packet routing algorithms for body sensor networks. In: Proceedings of 1st international conference on networks and communications, Chennai, India, pp 171-177. doi:10.1109/ NetCoM.2009.54

19. Movassaghi S, Abolhasan M, Lipman J (2007) Energy efficient thermal and power aware (ETPA) routing in body area networks. In: Proceedings of the IEEE 23rd international symposium on personal, indoor and mobile radio communications, Sydney, NSW, pp 1108-113. doi:10.1109/PIMRC20126362511

20. Liang X, Shen Q, Lu R, Lin X, Shen X, Zhuang W (2012) Exploiting prediction to enable secure and reliable routing in wireless body area networks. In: Proceedings of the 31st annual IEEE international conference on computer communications, Orlando, FL, USA, pp 388-396. doi:10.1109/INFCOM20126195777

21. Maskooki A, Soh CB, Gunawan E, Low KS (2011) Opportunistic routing for body area networks. In: Proceedings of the IEEE consumer communications and networking conference (CCNC'11) Las Vegas, NV, USA, pp 237-241. doi:10.1109/CCNC20115766463

22. Quwaider M, Biswas S (2010) DTN routing in body sensor networks with dynamic postural partitioning. Ad Hoc Netw 8(8):824-841. doi:10.1016/j.adhoc201003.002

23. Quwaider M, Biswas S (2009) Probabilistic routing in on-body sensor networks with postural disconnections. In: Proceedings of the 7th ACM international symposium on mobility management and wireless access. Tenerife, Canary Islands, Spain, pp 149-158. doi:10.1145/1641776.1641803

24. Uthra RA, Raja SV (2012) QoS routing in wireless sensor networks—a survey. ACM Comput Surv 45(1):9. doi:10.1145/2379776.2379785

25. Ayatollahitafti V, Ngadi MA, bin Mohamad Sharif J (2016) An efficient next hop selection algorithm for multi-hop body area networks. PLoS ONE 11(1):1-14. doi:10.1371/journal.pone.0146464

26. Kumaria J, Prachia (2015) An energy efficient routing algorithm for wireless body area network. Int J Wirel Microw Technol 5:56-62

27. Kaur HP, Goyal K (2015) Cost based efficient routing for wireless body area networks. Int J Comput Sci Mob Comput 4(8):295-300

28. Bangash Jl, Abdullah AH, Razzaque MA, Khan AW (2015) Critical data routing (CDR) for intra-wireless body sensor networks. TELKOMNIKA 13(1):181-192. doi:10.12928/telkomnika.v13i1.365

29. Gupta S, Kaur P (2015) WBAN health monitoring system using TEEN protocol: threshold sensitive energy efficient network protocol. Int J Innov Sci Eng Technol 2(10):20-25

30. Nedal A, Timmons N, Morrison J (2015) A cross-layer QoS-aware optimization protocol for guaranteed data streaming over wireless body area networks. Telecommun Syst 58(2):179-191. doi:10.1007/s11235-014-9901-8

31. Javaid N, Ahmad A, Khan Y, Khan ZA, Alghamdi TA (2015) A relay based routing protocol for wireless in-body sensor networks. Wirel Pers Commun 80(3):1063-1078. doi:10.1007/s11277-014-2071-x

32. Ahmed S, Javaid N, Akbar M, lqbal A, Khan ZA, Qasim U (2014) LAEEBA: link aware and energy efficient scheme for body area networks. In: Proceedings of the 28th IEEE international conference on advanced information networking and applications (AINA'14), Victoria, BC, pp 435-440. doi:10.1109/AINA201454

33. Ahmed S, Javaid N, Yousaf S, Ahmad A, Sandhu MM, Imran M, Khan ZA, Alrajeh N (2015) Co-laeeba: cooperative link aware and energy efficient protocol for wireless body area networks. Comput Hum Behav 51 (Part B):1205-1215 doi:10.1016/j.chb201412.051 
34. Cabacas R, Yang H, Ra IH (2014) Energy-efficient two-hop transmission prioritization scheme for wireless body area networks. In: Proceedings of the 15th IEEE international symposium on soft computing and intelligent systems (SCIS'14), Kitakyushu, pp 1213-1218. doi:10.1109/SCIS-ISIS20147044860

35. Sheth Mahammed Ovesh I, Sharma AK (2014) Modified LAEEBA routing in WBAN. Int J Sci Res Dev 2(8):348-351

36. Bangash Jl, Abdullah AH, Razzaque MA, Khanv AW (2014) Reliability aware routing for intra-wireless body sensor networks. Int J Distrib Sens Netw. doi:10.1155/2014/786537

37. Khan ZA, Sivakumar S, Phillips W, Robertson B (2014) ZEQoS: a new energy and QoS-aware routing protocol for communication of sensor devices in healthcare system. Int J Distrib Sens Netw. doi:10.1155/2014/627689

38. Khan ZA, Sivakumar S, Phillips W, Robertson B (2013) A QoS-aware routing protocol for reliability sensitive data in hospital body area networks. Procedia Comput Sci 19:171-179. doi:10.1016/j.procs201306.027

39. auqir A, Javaid N, Akram S, Rao A, Mohammad SN (2013) Distance aware relaying energy-efficient: DARE to monitor patients in multi-hop body area sensor networks. In: Proceedings of the IEEE 8th international conference on broadband and wireless computing, communication and applications (BWCCA'13), Compiegne, France, pp 206-213. doi:10.1109/BWCCA201340

40. Nadeem Q, Javaid N, Mohammad SN, Khan MY, Sarfraz S, Gull M (2013) Simple: stable increased-throughput multi-hop protocol for link efficiency in wireless body area networks. In: proceedings of the eighth international conference on broadband and wireless computing, communication and applications (BWCCA'13) Compiegne, pp 221-226. doi:10.1109/BWCC201342

41. Khan ZA, Sivakumar S, Phillips W, Robertson B, Javaid N (2012) QPRD: QoS-aware peering routing protocol for delay sensitive data in hospital body area network communication. In: Proceedings of the 7th international IEEE conference on broadband, wireless computing, communication and applications (BWCCA'12) Victoria, BC, Canada, pp 178-185. doi:10.1155/2015/153232

42. Alam MG, Hong CS (2012) A Q-learning based routing protocol for body area networks. DBPIA Korean Sch J 39(2):132-134

43. Ortiz AM, Ababneh N, Timmons N, Morrison J (2012) Adaptive routing for multihop IEEE 802.15.6 wireless body area networks. In: Proceedings of the 20th international conference on software, telecommunications and computer networks (softCOM'12) Split, Croatia, pp 1-5

44. Bayilmis C, Younis M (2012) Energy-aware gateway selection for increasing the lifetime of wireless body area sensor networks. J Med Syst 36(3):1593-1601. doi:10.1007/s10916-010-9620-y

45. Khan Z, Aslam N, Sivakumar S, Phillips W (2012) Energy-aware peering routing protocol for indoor hospital body area network communication. Procedia Comput Sci 10:188-196. doi:10.1016/j.procs201206.027

46. Elias J, Mehaoua A (2012) Energy-aware topology design for wireless body area networks. In: Proceedings of the IEEE international conference on communications, Ottawa, ON, pp 3409-3413. doi:10.1109/ICC20126363949

47. Ababneh N, Timmons N, Morrison J, Tracey D (2012) Energy-balanced rate assignment and routing protocol for body area networks. In: Proceedings of the 26th IEEE international conference on advanced information networking and applications workshops. Fukuoka, pp 466-471. doi:10.1109/WAINA201234

48. Liang L, Ge Y, Feng G, Ni W, Wai AAP (2012) Experimental study on adaptive power control based routing in multihop wireless body area networks. In: Proceedings of the global communications conference. Anaheim, CA, pp 572-577. doi:10.1109/GLOCOM20126503174

49. Tsouri GR, Prieto A, Argade N (2012) On increasing network lifetime in body area networks using global routing with energy consumption balancing. Sensors 12(10):13088-13108. doi:10.3390/s121013088

50. Razzaque MA, Hong CS, Lee S (2011) Data-centric multi objective QoS-aware routing protocol for body sensor networks. Sensors 11(1):917-937. doi:10.3390/s110100917

51. Cheng S, Huang C, Tu CC (2011) RACOON: a multiuser QoS design for mobile wireless body area networks. J Med Syst 35(5):1277-1287. doi:10.1007/s10916-011-9676-3

52. Seo SH, Gopalan SA, Chun SM, Seok KJ, Nah JW, Park JT (2010) An energy-efficient configuration management for multihop wireless body area networks. In: Proceedings of the 3rd IEEE international conference on broadband network and multimedia technology (IC-BNMT'10) Beijing, pp 1235-1239. doi:10.1109/ICBNMT20105705287

53. Kim DY, Kim WY, Cho JS, Lee B (2010) EAR: an environment-adaptive routing algorithm for WBANs. In: Proceedings of the international symposium on medical information and communication technology (ISMICT'10)

54. Djenouri D, Balasingham I (2009) New QoS and geographical routing in wireless biomedical sensor networks. In: Proceedings of the 6th international conference on broadband communications, networks, and systems. Madrid, Spain, pp 1-8. doi:10.4108/ICST.BROADNETS20097188

55. Liang X, Balasingham I, Byun SS (2008) A reinforcement learning based routing protocol with QoS support for biomedical sensor networks. In: Proceedings of the 1st international symposium on applied sciences on biomedical and communication technologies. Aalborg, Denmark, pp 1-5. doi:10.1109/ISABEL20084712578

56. Liang X, Balasingham I (2007) A QoS-aware routing service framework for biomedical sensor networks. In: Proceedings of the 4th IEEE international symposium on wireless communication systems. Trondheim, pp 342-345. doi:10.1109/ISWCS20074392358

57. Lazzi G (2005) Thermal effects of bioimplants. IEEE Eng Med Biol Mag 24(5):75-81

58. Takahashi D, Xiao Y, Hu F (2007) LTRT: least total-route temperature routing for embedded biomedical sensor networks. In: Proceedings of the IEEE global telecommunications conference. Washington, DC, USA, pp 641-645. doi:10.1109/GLOCOM2007125

59. Tang Q, Tummala N, Gupta SK, Schwiebert L (2005) TARA: thermal-aware routing algorithm for implanted sensor networks. In: Proceedings of the 1st IEEE international conference distributed computing in sensor systems. Marina del Rey, CA, USA, pp 206-217. doi:10.1007/11502593_17

60. Bag A, Bassiouni MA (2007) Hotspot preventing routing algorithm for delay sensitive biomedical sensor networks. In: Proceedings of the IEEE international conference on portable information devices, Orlando, FL, pp 1-5. doi:10.1016/j.inffus200702.001

61. Rafatkhah O, Lighvan MZ (2014) $\mathrm{M}^{2} \mathrm{E}^{2}$ : a novel multi-hop routing protocol for wireless body sensor networks. Int J Comput Netw Commun Secur 2(8):260-267 
62. Ahmed A, Javaid N (2014) RE-ATTEMPT: energy-efficient routing protocol for wireless body area sensor networks. Int J Distrib Sens Netw. doi:10.1155/2014/464010

63. Monowar MM, Mehedi Hassan M, Bajaber F, Hamid MA, Alamri A (2014) Thermal-aware multiconstrained intrabody QoS routing for wireless body area networks. Int J Distrib Sens Netw. doi:10.1155/2014/676312

64. Ahmed A, Javaid N (2014) RE-ATTEMPT: energy-efficient routing protocol for wireless body area sensor networks. Int J Distrib Sens Netw. doi:10.1155/2014/464010

65. Tabandeh M, Ahourai F, Moradi S, Jahed M (2009) A thermal-aware shortest hop routing algorithm for in vivo biomedical sensor networks. In: Proceedings of the IEEE sixth international conference on information technology: new generations, Las Vegas Naveda, pp 1612-1613. doi:10.1109/ITNG2009274

66. Anirban B, Bassiouni MA (2008) Routing algorithm for network of homogeneous and id-less biomedical sensor nodes (RAIN). In: Proceedings of the IEEE sensors applications symposium, Atlanta, GA, USA, pp 68-73

67. Anirban B, Bassiouni MA (2006) Energy efficient thermal aware routing algorithms for embedded biomedical sensor networks. In: Proceedings of the IEEE international conference mobile ad hoc and sensor systems (MASS'06) Vancouver, BC, Canada, pp 604-609. doi:10.1109/MOBHOC2006278619

\section{Submit your manuscript to a SpringerOpen ${ }^{\odot}$ journal and benefit from:}

- Convenient online submission

- Rigorous peer review

- Open access: articles freely available online

- High visibility within the field

Retaining the copyright to your article

Submit your next manuscript at $\boldsymbol{\Delta}$ springeropen.com 